\title{
(Micro)territorialidades: metáfora dissidente do social
}

\section{(Micro)territorialities: dissenting metaphor on the social}

\author{
Carlos Fortuna \\ cjfortuna@gmail.com \\ Universidade de Coimbra
}

Resumo: As (micro)territorialidades são consideradas neste texto como modalidades de sociação articuladas em torno a valores, subjetividades e afetos. Distinguem-se, assim, das modalidades de associação convencionais e revelam-se capazes de acolher formas de reorganização social não-institucional e, sobretudo, transformações radicais de valores e estilos de vida. Enquanto visões fragmentares da vida urbana metropolitana, todavia, como se procura argumentar, as (micro)territorialidades podem contribuir para um entendimento mais adequado e inovador da cidade/metrópole de hoje.

Palavras-chave: (micro)territorialities. Subjetividade. Afetos. Metrópole.

Abstract: (Micro)territorialities are taken here as modes of sociation around values, subjectivities and affects. Hence, (micro)territorialities differ from conventional forms of association and are able to contain forms of non-institutionalized social re-organization, including radical change in values and lifestyles. As fragmented views of urban life, though, (micro)territorialities may contribute toward a more accurate and creative understanding of today's city/metropolis.

Keywords: (Micro)territoriality. Subjectivity. Affections. Metropolis.

Resumen: Las (micro) territorialidades son consideradas en este texto como modalidades de asociación articuladas en torno de los valores, las subjetividades y afectos. Se distingue, así, de las modalidades de asociación convencionales y se revelan capaces de acoger formas de reorganización social no institucional $\mathrm{y}$, sobre todo, cambios radicales de valores y estilos de vida. Mientras las visiones de la vida urbana metropolitana fragmentada, sin embargo, como si procura argumentar, las (micro) territorialidades pueden contribuir a una comprensión más adecuada y innovadora de la ciudad/metrópoli de hoy.

Palabras clave: (Micro)territorialidad. Subjetividad. Afectos. Metrópoli. 


\section{INTRODUÇÃO}

Quando fui desafiado a refletir sobre ${ }^{1}$ as "(micro)territorialidades das cidades", pensei em subordinar o meu texto à explicitação da relação entre espaços, discursos e usos sociais dos espaços situados entre os edifícios da cidade. Faria deles o objeto central da reflexão sobre (micro)territorialidades, procurando dialogar com a história e o discurso da arquitetura. Na verdade, estou convencido que, sem desprimor para os arquitetos, os seus livros dizem menos do que poderiam sobre o caráter das cidades, precisamente porque a sua atenção fica concentrada nos edifícios, na sua estética e funcionalidade, oferecendo relatos desligados dos espaços e dos lugares sociais, pelo que não tratam da história nem a dinâmica atual das cidades. Pensei, portanto, em arriscar entrar no campo dos espaços ordinários que se encontram entre os edifícios das nossas cidades e das semânticas usadas para traduzir o seu sentido e decifrar os (micro) usos sociais que suportam. Era uma maneira de desenvolver a ideia de (micro)territorialidade que marca a organização deste seminário.

Acabei por optar pela ideia inicial, adaptando-a após consulta aos dicionários acadêmicos habituais que, na verdade, não dedicam entrada própria à noção de (micro) territorialidade. Limitam-se tão somente a referi-la como sinônimo de territorialidade, procurando fazer a sua equivalência a "espaço delimitado", "proximidade física", "contiguidade", "nativismo" etc., que indiciam práticas e discursividades sociais subalternizadas. Olhei, então, aleatoriamente, os títulos das outras comunicações. A variedade temática era assinalável, sem deixar de enunciar também uma atitude epistemológica e política alternativa: "desafinando o coro dos contentes”, “identidades na areia”, " gênero e posicionalidade", "parada LGBT", "moto clubes", para só mencionar alguns.

Decidi, por fim, animado pela variedade dos entendimentos sobre as (micro)territorialidades e aconselhado por algum pragmatismo, refletir livremente sobre o sentido a atribuir ao vocábulo. Encontrei, no entanto, duas delimitações: por um lado, sujeitar as (micro)territorialidades ao confronto, ainda que apenas como estratégia de enquadramento, com as macroestruturas e, por outro lado, aproximando-me claramente do tema fornecido pelos organizadores do Seminário, inseri-las na realidade urbana e metropolitana, ela própria traduzível em realidade ou em experiência de escala macro.

Quanto à primeira destas referências, que entretanto não desenvolverei, entendi pautar a reflexão que faço considerando que as territorialidades na sua escala micro refletem o diálogo entre um tempo denso e longo próprio do estudo das macroestruturas e das espacialidades da modernidade capitalista que recobrem processos globais como os longos ciclos dos mercados, a dinâmica dos impérios ou os processos sociopolíticos de larga escala, como as relações centro-periferia. Do outro lado, defini como limite da minha reflexão, o tempo precário e curto típico dos ritmos nervosos da vida sensível e dos microacontecimentos sociais que, de acordo com vários estudiosos consagrados, está

1 Este texto foi organizado originalmente para o I Seminário Internacional sobre Microterritorialidades nas Cidades, que teve lugar na UFRJ, no Rio de Janeiro. 
reganhando atualidade como mostram as análises sobre o corpo, a memória, as identidades e o seu fim, os sentidos, a afetividade etc., todos objetos sujeitos a espacializações condicionantes do seu significado.

As territorialidades micro que discuto são, portanto, subsidiárias deste "encontro" de processos socioespaciais situados na confluência interescalar do macro e do micro. ${ }^{2}$ São também fenômenos situados nos lugares ou, mais objetivamente, em espaços de pequena escala com gente dentro, o que lhes confere, em consequência, uma dimensão humana e territorial particular. Mas é precisamente a qualidade de imprimir expressão humana e social a estes espaços, incluindo os "espaços" virtuais, que confere a estas territorialidades a natureza eminentemente social que ostentam.

Devo chamar a atenção para a tradição da sociologia que há muito identificou as comunidades e as sociedades como formas elementares de sociação. Estas categorias dialógicas, propostas por Ferdinand Tönnies (1972), referem-se porém a modalidades de pertencimento muito especiais. Ser membro de uma comunidade nacional ou grupo étnico não é um ato deliberado de vontade individual e resulta do que podemos considerar ser o peso da tradição. Por outro lado, pertencer a uma sociedade, por exemplo, um grupo religioso, político ou desportivo, é uma escolha feita com recurso à avaliação racional dos sujeitos. O sentido que pretendo dar às (micro)territorialidades, sem desprezar por completo estas formas clássicas de agremiação, está próximo da proposta do sociólogo alemão Herman Schmalenbach $(1977)^{3}$ que recorre a uma terceira categoria de coletividade - as associações ou Bünde - baseada na partilha de afetos, sentimentos e emoções e não na tradição ou na racionalidade. A matriz primordial destas associações afetivas denota alguma alternatividade e dissidência perante os modos convencionais de ler o social, nomeadamente a díade comunidade-sociedade. Ela se mostra propícia ao enquadramento do descontentamento contemporâneo, assim como ao reequacionamento das recentes redefinições da importância dos valores, subjetividades e afetos no desenrolar da vida social (CLOUGH; HALLEY, 2007; STEWART, 2007). No limite, estas formas de sociação podem acolher modalidades renovadas de ver o mundo e de organização social não-institucional e, sobretudo, transformações radicais de comportamentos e estilos de vida (COHEN, 1983, citado em HETHERINGTON, 1998, p. 88).

Neste sentido, as (micro)territorialidades que desejo trazer à discussão podem ser as teias de relações consistentes que se desenrolam nas praças ou esquinas da cidade ou no recato da domesticidade de proximidade que o "pedaço" representa. Podem igualmente ser as comunidades afetivas, muitas delas concretizadas tanto nas subjetividades ou na imaginação dos sujeitos como nos territórios ausentes que tipificam as comunidades virtuais ou alguns movimentos diaspóricos.

2 Ao lado destas delimitações, devo ressalvar o meu débito aos trabalhos de reconceitualização de muitos geógrafos críticos, desde Doreen Massey a Nigel Thrift, passando por Milton Santos, Rogério Haesbaert da Costa ou Henri Acselrad, cujos escritos se revelam por demais atentos aos contributos culturais e filosóficos sobre o entendimento do elemento espacial e territorial na vida social dos nossos dias.

3 Desprezado, a meu ver, injustificadamente, o trabalho de Herman Schmalenbach foi recentemente reabilitado, principalmente a sua noção de "associação afetiva" (Bund) (Hetherington, 1998). O conhecido trabalho de Michel Maffesoli (O tempo das tribos) (Maffesoli, 1988) é claramente inspirado nas propostas de Schmalenbach, ainda que não explicitadamente. 
Em todas as circunstâncias estas (micro)territorialidades são fenômenos de escala urbana, em alguns dos casos mesmo de escala metropolitana. É nesta pauta da cultura urbana que faz sentido discutir as estratégias dos sujeitos e grupos que tecem as suas (micro) territorialidades. Umas podem ser de sinal político conservador, outras progressistas. Estas últimas referem-se aos "outros espaços", no sentido que lhes dá Michel Foucault (1986), que constituem arenas de práticas e discursividades plurais subalternizadas e resistentes à homogeneização. São lugares onde os usuários manifestam a sua recusa em ser recusados e desenvolvem estratégias de afirmação identitária alternativa. Muitos dos espaços vazios (material e socialmente) das cidades e metrópoles, situados à margem dos processos de regulação e ordenamento urbano, ao serem investidos de novas práticas e significados, constituem uma zona de indeterminação e contingência que funciona como (micro)territorialidade ativa, quer dizer, capaz de mobilizar energias e de produzir ação social. É neste sentido que podemos considerá-las visões dissidentes do social.

As (micro)territorialidades têm um sentido particular de confrontação com o contexto excessivo da metrópole. Enquanto macroestrutura urbana, a metrópole de hoje apresenta uma complexidade distintiva que faz com que não só não seja um espaço de intimidade, como represente um espaço de profunda fragmentação social, espacial e cultural (FORTUNA, 2011). Até do ponto de vista sensorial, a metrópole é excessiva no sentido em que excede a capacidade de perceção humana, desde logo a perceção visual. Tornou-se impossível ter uma visão "pan-orâmica" da metrópole que transbordou para além do horizonte. Só podemos ter dela uma imagem fragmentada.

$\mathrm{Na}$ medida em que as (micro)territorialidades constituem fragmentos organizados de sociação territorializada, elas podem ser capazes de concorrer para a refocagem da totalidade da cidade/metrópole. Essa capacidade investe as (micro)territorialidades de alguma "perigosidade" e rebeldia ao disputar as visões "globais", que são as visões hegemônicas institucionalizadas do mundo urbano. Permitem ver aquilo que vai sendo deliberadamente obscurecido e revelam mecanismos de produção da presença de muitos sujeitos e grupos subalternizados, assim como tornam audíveis discursividades indesejadas.

Será realmente a imagem produzida a partir das (micro)territorialidades a mais adequada a captar a cidade/metrópole excessiva de hoje? Este é o argumento que gostaria de testar. As (micro)territorialidades, entendidas como espacialidades socioafetivas de pequena escala, ao mesmo tempo que revelam a tremenda profusão da cultura urbana, constituem um patrimônio socio-antropológico pouco trabalhado que amplia e desdobra os nossos horizontes compreensivos sobre a realidade metropolitana contemporânea.

O que estou a propor é avaliar a possibilidade de trazer as (micro)territorialidades para o centro da discussão atual e olhar a cidade/metrópole do ponto de vista do fragmento. Esse fragmento são muitos e diversos fragmentos que conservam a virtude de poderem contribuir com a sua visão própria para a (re)visão da episteme urbana que autorizará um melhor e mais adequado entendimento do que é a cidade/metrópole de hoje. 


\section{CONSIDERAÇÕES GERAIS SOBRE (MICRO)TERRITORIALIDADES}

A abordagem ao tema das (micro)territorialidades é certamente subsidiária da geografia, mas não limitada a ela. As dimensões sociais, culturais e filosóficas do território implicam o alargamento do seu significado, aproximando-o de noções mais plásticas, simbólicas e expressivas que não são, como sabemos, as mais diretamente associadas à geografia. ${ }^{4}$

A noção de (micro)territorialidade implica uma abordagem multiescalar dos espaços e o reconhecimento dos micropoderes de que fala Foucault em contraponto ao poder macro do estado e a sua territorialidade por excelência: o espaço nacional da modernidade. Não me deterei sobre isso e sublinho antes o fato de entender a territorialidade como representação ou "subjetivação" do território que remete a uma espécie de geografia emocional que transmite ao espaço uma enorme carga afetiva. É como se o território enquanto macroestrutura fosse convertido em microespaço e fizesse parte efetiva de nós, como se fosse a nossa casa ou o lugar geodésico da nossa existência. Este território dentro de nós envolve uma noção nova de geografia e de espacialidade, porquanto a subjetivação do território, agora constituído por novos enclaves e paisagens emocionais, impõe um novo regime de interesses, reivindicações e exigências de cada grupo ou sujeito (JAMESON, 1991). Um forte investimento afetivo nesse território subjetivado traduz um particularismo político e emotivo que impõe uma forma diferente de enunciar o outro e, por essa via, uma outra forma de autoenunciação dos sujeitos. As célebres praças e ruas das cidades da Primavera Árabe de 2011, ou os lugares singulares dos indignados de Madrid ou de Nova Iorque constituem hoje lugares simbólico-afetivos e, nesse sentido, identitários, da nova condição de rebeldia política (SASSEN, 2011). São hoje microterritórios com renovada fisionomia política e cultural que, podemos dizer, parecem estar dentro de cada um dos jovens ativistas que os animam. Originalmente destituídos de qualquer uniformidade de sentidos políticos, simbólicos e afetivos esses novos territórios convertem-se numa espécie de "espaço de compensação" (a noção é de THAI, 1997) para indivíduos e grupos dispersos que se (re)encontraram na territorialidade alternativa que representam aquelas ruas e praças face às práticas espaciais confinadas e convencionais.

Estamos perante um processo de territorialização do sensível que representa um dos aspetos heuristicamente mais valiosos do estudo das espacialidades urbanas, incluindo as territorialidades micro (RODAWAY, 1994; DEGEN, 2008; FORTUNA, 2009a). Neste particular, é devida a Henri Lefebvre e ao método da ritmanálise (LEFEBVRE, 1991 e 2002) com o qual o filósofo francês procurou, na parte final de sua vida, decifrar premissas anteriores sobre a relação entre o corpo e o espaço. O seu ponto de partida é que o espaço social é constituído e experimentado, em primeiro lugar, com base em nossa corporeidade sensível (LEFEBVRE, 1961; JEUDY; JACQUES, 2006).

4 No entanto, devo ressalvar o meu débito aos trabalhos de reconceitualização de muitos geógrafos críticos, desde Doreen Massey a Nigel Thrift, passando por Milton Santos, Rogério Haesbaert da Costa ou Henri Acselrad, cujos escritos se revelam atentos aos contributos culturais e filosóficos sobre o entendimento do elemento espacial e territorial na vida social contemporânea. 
A ritmanálise de Lefebvre celebra a interação de dois processos distintos: de um lado, a atividade física (movimentos e ritmos cotidianos, incluindo os relacionados ao trabalho, que marcam as práticas espaciais cotidianas dos sujeitos) e, do outro lado, a experiência sensorial (a visão, o olfato, o ouvido, o tato e mesmo o gosto de cada um). $\mathrm{Na}$ sua confluência, ambos os processos contribuem para a produção de paisagens sensoriais que são vividas com intensidade variável em resultado das reciprocidades (físicas e sensoriais) que estabelecem entre si. Um dos mais valiosos contributos de Lefebvre, aliás comum a trabalhos de vários representantes da teoria do ator-rede, reside na convicção de que os sentidos não funcionam por si próprios, desligados do mundo exterior, e requerem, portanto, uma estimulação externa que só o mundo material dos objetos pode fornecer. Neste sentido, as territorialidades representam parte da materialidade com que constituímos e percecionamos a nossa condição social. Daqui resulta uma nova interpretação do social que não se justifica apenas por uma causalidade humana mais ou menos difusa e implica uma noção alternativa de interação e imbricação com o mundo material dos objetos, dos espaços e das tecnologias (LATOUR, 2000).

Isso supõe uma revisão da noção de agência, vista como concretização da ação material dos sujeitos. Agência não remete apenas às circunstâncias exclusivamente humanas da ação, já que passa a estipular um social entendido como mútua interseção entre pessoas e objetos (URRY, 2000, p. 78). Esta materialidade do social não significa qualquer limitação da capacidade de subjetivação dos sujeitos nem o fim do seu recurso à memória dos lugares. Tais mecanismos são vertidos sobre a vida material de tal modo que cada um desses dois mundos (humano e material) se encontra intimamente incorporado na agência ou realização do outro.

O uso dos sentidos faz parte da identidade dos sujeitos que reagem e mobilizam as suas capacidades sensoriais em conformidade com os estímulos recebidos pela materialidade do mundo exterior, designadamente o contexto espacial-territorial em que estão inseridos. Numa sociedade que privilegia o movimento, a identidade dos sujeitos não pode ser entendida apenas como efeito direto dessa materialidade do lugar e comporta também um sentido particular de acúmulo de múltiplas identificações momentâneas e circunstanciais, espacialmente situadas, que os sujeitos apropriam. Essa identidade desessencializada que se encontra já nas clássicas incursões sociológicas de Simmel, feitas nos princípios do século XX, constitui um dos aspetos marcantes da relação do corpo com o espaço material na modernidade.

A questão é deveras instigante quando pensamos nas territorialidades sem território em que a materialidade constitutiva da identidade dos sujeitos está ausente e pode, quando muito, ser imaginada ou tornada virtual. Como pode um território ausente ser constitutivo de uma identidade política ou ideológica? A história da comunidade judia anterior à constituição do Estado de Israel é um bom exemplo de uma identidade política construída na ausência de um território concreto que, não obstante, não deixou de exercer a função de um potente mobilizador da ação. A narrativa do retorno dos escravos afro-americanos à Libéria, ou o movimento rastafári, que proclama um outro regresso redentor às origens territoriais (e filosóficas) da África oriental, são outros exemplos desta 
territorialidade sem território ou territorialidade imaginada. Em geral, as diásporas e os fenômenos migratórios retêm também esta referência de territorialidade como desígnio de vida, como no caso da emigração portuguesa que, tratada com frequência como subordinada ao mito "eterno retorno" - levado ao paroxismo no caso do mito do sebastianismo -, isto é, de um regresso prometido e sempre adiado à origem, ou se quisermos a casa que, como afirmamos antes, sabemos, constitui o lugar antropológico identitário primordial.

O conjunto de símbolos e mitificações feitas em torno do estado-nação é outra das variáveis desta territorialidade ausente. Esse é o argumento de Benedict Anderson ao sublinhar a vontade de construção dos estados-nação da modernidade, com base nas "comunidades imaginadas" (ANDERSON, 1983). A materialidade que mobiliza a ação de muitos grupos, comunidades e nações é, nestes casos, uma materialidade simbólica ou discursiva e performativa que agencia práticas e rituais com tradução efetiva na ação dos sujeitos. Nos discursos da pós-colonialidade encontram-se numerosas narrativas sobre a pós-memória em que os sujeitos atuam guiados por uma representação coletiva mitificada de uma comunidade sem existência material concreta.

A materialidade das (micro)territorialidades, mesmo quando apenas subjetivada, pode representar um eixo determinante das identidades coletivas. Nesta sequência, podemos recordar a alegoria de Walter Benjamin em torno ao "anjo da história" - o Angelus Novus de Paul Klee - que estabelece ressonâncias manifestas com a ideia de territorialidade sem território. Para Benjamin, a viagem do Angelus Novus em direção ao futuro é uma viagem alucinante porque desconhece o seu destino e duvida dele (BENJAMIN, 1968). Com efeito, o sujeito da modernidade que o Angelus Novus representa, viaja de marcha à ré e, do seu destino nada sabe, pois só consegue enxergar a decadência e a ruína que vão ficando para trás. Aterrorizado com o que irá encontrar no final de seu trajeto, a expressão do seu horror é sinal de um destino futuro de destruição que o seu passado vivido pressagia.

A modernidade constitui-se aqui em território metafórico que autoriza imaginar uma relação - isto é, uma territorialidade - em tudo semelhante à narrativa que descreve a demanda da cidade dos camponeses medievais alemães além-Elba. Desejosos por escapar ao jugo autoritário dos poderosos senhores feudais e empenhados em afirmar a sua autonomia pessoal, buscam na cidade o território emancipatório onde concretizarão a sua libertação. O seu mote - Statdluft macht frei! (Os ares da cidade libertam) - revelar-se-ia, porém, um mito na medida em que a fuga a uma condição de subjugação daria lugar a outras condições de subalternidade, apesar de terem logrado trocar de territórios. Temos aqui, portanto, uma construção de cidade como territorialidade emancipatória que, como é sabido, não deixou até hoje de ser objeto de contestação e tem feito correr rios de tinta conservadora (FORTUNA, 2009a).

Tal como o Angelus Novus a caminho da sua nova territorialidade se encontra destinado, segundo Walter Benjamin, a confrontar-se com um "progresso" no mínimo duvidoso, também os camponeses alemães viram defraudados os desígnios da afirmatividade individual e de grupo que procuravam concretizar no contexto da cidade conquistada. 
Ambas as referências nos levam a pensar no lugar dos sujeitos modernos inseridos nas comunidades virtuais. Enquanto territorialidades micro, estas comunidade virtuais asseguram um constante entrar e sair dos sujeitos que assim multiplicam e modulam a cada momento as suas identidades e as suas visões do mundo. Estes "nómadas digitais" dedicam-se a alimentar um incessante número de conexões virtuais e, nesse ato, produzem e ampliam também eles um espaço de relação efêmera e laços fracos, isto é, uma territorialidade "não real" (MAKIMOTO; MANNERS, 1997).

Com esta afirmação, desejo assinalar a necessária relativização que se impõe acerca da interpretação que atribui às sociedades contemporâneas, organizadas em torno ao mercado e ao anonimato e em que as tecnologias digitais são determinantes, a capacidade de gerar "cumplicidade frias" e "padrões de solidariedade fracos" (SASSEN, 2006, p. 141). O exemplo já referido da mobilização social nos países da faixa africana-mediterrânica, conseguida por meio dos novos recursos ou redes sociais de comunicação, pode bem contrariar a convicção de que só as sociedades pré-modernas, de grande estabilidade relacional podem gerar solidariedades densas e intensas. Muitos dos mais recentes movimentos de contestação política urbana articulam de modo criativo a energia das territorialidades concretas das cidades - suas ruas e praças públicas - aliando-a ao potencial das territorialidades imaginadas, como as redes eletrônicas e as conexões virtuais.

Não tenho intenção de insistir nesta visão das territorialidades imaginadas ou representadas, desvinculadas da dimensão material do território (do tipo Angelus Novus, demanda de direitos na fuga para a cidade medieval, ou comunidades virtuais). Mas pretendo afirmar que a imaginação das territorialidades pode resultar e ser produzida a partir de outras situações territoriais vinculadas a espaços materiais concretos, referidos a lugares com existência e significado também reais e não a espaços idealizados ou indiferenciados da cena urbana.

Neste caso, a reflexão toma a direção dos significados atribuídos aos espaços materiais da vida social. Para essa breve reflexão, recorro à distinção convencional entre espaço e lugar, tal como estipulada pelo acadêmico sino-americano Yi-Fu Tuan. Para Tuan (1983), o espaço indiferenciado das cidades torna-se lugar sempre que proporciona a paragem no meio do movimento cotidiano e, desse modo, convida a um mais profundo conhecimento do local e mesmo à identificação dos sujeitos com ele. $\mathrm{O}$ espaço equivale à noção de movimento, em oposição ao lugar que é sinônimo de paragem, segurança e estabilidade. Gostaria de admitir aqui, no entanto, que o lugar, assumido como a territorialidade da segurança ontológica e da estabilidade, funciona contudo como o patamar a partir do qual se pode ambicionar a abertura e a liberdade. Admitimos que a estabilidade e a segurança oferecidas pelas (micro)territorialidades, entendidas estas como espaços circunscritos de intimidade pessoal ou grupal, podem revelar-se ameaçadoras para a afirmação social da individualidade. Foi a partir dessa premissa, aliás, que se produziu toda a narrativa acerca da "tirania da comunidade" (SENNETT, 1977) que continua a alimentar o sonho de estabilidade e afirmação pessoal de muitos indivíduos e grupos que veem numa cobiçada condição cosmopolita a garantia da sua emancipação. 
A distinção entre espaço/movimento e lugar/estabilidade parece não abrir novas possibilidades no jogo das territorialidades micro. Sabemos como tal distinção se encontra subjacente à noção de "não-lugar" que Marc Augé adotou da retórica jurídica francesa - em que significa insuficiência de prova - para a aplicar aos espaços indiferenciados, sem história nem memória que, por isso, não autorizam ou limitam drasticamente qualquer exercício de cidadania: shoppings, autopistas, aeroportos, etc. (AUGÉ, 1992). Inspirado em Siegfried Kracauer e em Paul Virilio, o ensaísta dinamarquês Henrik Reeh produziu um notável texto sobre a intensidade emocional e histórica que pode ser experimentada no banal cotidiano de aeroportos e estações ferroviárias (REEH, 2009). Recuando aos tempos de Berlim numa Alemanha fraturada, Reeh demonstra como esses "não-lugares" estão cheios de vida social e promovem insuspeitados investimentos emocionais, em grande parte alimentados pela memória e a fantasia da experiência da chegada e da partida. Hoje tornados atos prosaicos da vida moderna, essa chegada e partida mostra que, assegura Reeh, "a memória individual ou coletiva pode a qualquer instante dar-se conta da capacidade sensorial e da energia da experiência contidas na viagem ao aeroporto" (REEH, 2009, p. 67).

Entendo que vale resgatar este exemplo para o elenco das (micro)territorialidades que podem fomentar fortes investimentos pessoais à medida que são experienciados, ou conquistados, a um tempo, pela mente e pelo corpo. É nessa condição que essas territorialidades permitem sonhar. São espaços que parecendo vazios - terra nullius - revelam tanta inércia como movimento (SANSOT, 1994), ao mesmo tempo que garantem um elevado grau de satisfação pessoal a quem se disponha a neles investir social, emotiva e culturalmente.

A eponímia é a expressão desse investimento simbólico radical. Com efeito, a (auto) nomeação de alguns lugares continua a ser um fator importante do reconhecimento da sua relação com os sujeitos e a sociedade em geral. A transformação de espaços indiferenciados em territorialidades expressivas através da atribuição de um nome ou de uma "marca" é uma estratégia de significação que, ontem como hoje, procura conferir sentido de identidade e apropriação. Quer se trate das espacialidades delimitadas dos estados nacionais, quer do bairro popular ou do "pedaço", essa urbanidade de proximidade e de reconhecimento intimista, a nomeação é essencial para a criação de lugares novos. Pensemos nas viagens dos navegadores e no modo como estes, chegados à costa, trataram de nomear lugares, num exercício político de dominação e simultânea confirmação de si. O espaço tornado lugar pela sua nomeação, não raramente por exercício eponímico, pode ser ilustrado pelo "estreito de Magalhães" ou a "passagem de Drake", por exemplo. Com essa inscrição, o lugar ganha um significado humanizado e ampliado, fazendo recordar a diferença que Henri Lefebvre estabeleceu entre "espaço social" e "espaço absoluto". Outras situações de de-marcação dos lugares são, por exemplo, os graffiti, que autenticam a cidade e os artistas que os assinam, sendo também comuns as de-marcações feitas pela simples presença ostensiva de sujeitos em lugares urbanos desativados (prédios devolutos, passagens subterrâneas, terrenos baldios e outros espaços entre os edifícios). 
Esta dimensão cultural dos microterritórios, entendida como interpretação do significado do lugar pode-se tornar simples paisagem. A paisagem que surgiu com a cultura "ótica" influenciada pela pintura renascentista e os avanços das novas técnicas de navegação de Veneza e Flandres não é senão a representação do espaço exterior que pode enxergar-se a partir de um ponto dado. Nesta nova referência aos sentidos, vale afirmar que a topografia que assinala o que vemos, se distingue da visão, que traduz o modo como vemos. Para ver a paisagem, precisamos estar distantes e fora dela, o que pode limitar a capacidade de julgamento das (micro)territorialidades por parte dos sujeitos que as constituem e lhes dão existência e sentido. A famosa gravura do "geógrafo" de Johannes Veermer (1632-1675) ilustra o modo como esta distância constitui uma competência analítica na decifração/representação da paisagem. É um exercício oposto à decifração do lugar que se deixa captar a partir de dentro, exigindo proximidade para ser vivenciado realmente.

As paisagens, como sustenta Edvânia Gomes "só existem para quem as representa, independentemente das forças e interesses que movem esse olhar" (GOMES, 1997: 23, cit. In: ANDRADE, 2007). A implicação imediata desta alusão à relação proximidade/ distância das (micro)territorialidades surge documentada nas mais diversas narrativas, tanto literárias como socioantropológicas, centradas nas personagens que regressam ao lugar de origem depois de ausência prolongada. A ilação a recolher das premissas enunciadas é que, no seu regresso, os "retornados" só podem vivenciar o lugar enquanto paisagem, ou seja, não conseguem participar efetivamente no desenrolar de suas dinâmicas e permanecem ausentes da vida real do lugar. Na verdade, esses são sujeitos tornados outsiders por quem está dentro e só nessa condição podem "participar" caucionados pela tolerância e a indiferença dos locais "reais". Não habitamos as paisagens... apenas as visualizamos. Não habitamos o sentido de territorialidade dos lugares, apenas o podemos projetar mental e culturalmente.

A territorialidade do microlugar é também um modo ver, uma tecnologia muito particular do olhar, apta a traduzir e dar significado ao mundo. Vemos modos de estar, relações de pessoas com outras e com os territórios. São todas experiências e contextos de significação irrepetíveis, ou apenas replicáveis pela massificação da cultura, que tornam incomensuráveis os seus significados. O lugar e a sua territorialidade cultural representa, assim, dada a pluralidade de significados envolvidos, uma forma de resistência progressista à homogeneização provocada pela globalização e a sua retórica. Progressista, na medida em que produz um olhar de singularidade, diferente, alternativo e dissidente. Seria, ao contrário, sinal de atitude conservadora se o "nosso" território fosse interpretado como estando sob a ameaça de "outros", vindos de fora, e induzisse fechamento da comunidade sobre si própria, erigindo barreiras e interditos. Esse é o embrião das territorialidades conservadoras que conduziram às mais trágicas expressões de racismo e xenofobia e às ações dramáticas de exclusão, como o "ghetto". 


\section{3 (MICRO)TERRITORIALIDADES E (RE)FUNCIONALIZAÇÃO SOCIOESPACIAL}

Gostaria de admitir que as (micro)territorialidades podem induzir processos de (re)funcionalização de espaços, tornando-os aptos para atividades originalmente não previstas. Penso em espaços de acesso não restrito e funcionalmente flexíveis, sobre os quais são investidos múltiplos sentidos que aumenta a sua resposta às necessidades sociais de seus atuais usuários. Estes espaços são aqueles que escapam às lógicas do planejamento urbano e da regulação institucional, em resultado do que traduzem uma "interrupção" da malha urbana.

É o caso dos vestígios da cultura pós-industrial, como sejam a fábrica abandonada, o galpão desativado, ou o edifício em ruínas. Todos ilustram a falência de anteriores mundos sociais e modos de estar e de fazer. As marcas da presença humana organizada que ali teve lugar, podem abrigar agora sinais desorganizadamente situados de outros e, por vezes, surpreendentes usos por parte de grupos particulares (uns marginais e delinquentes, outros simplesmente derrotados pela modernidade, como as pessoas sem-teto) (EDENSON, 2005). Trata-se de espaços distópicos que parecem "vazios urbanos" e sinalizam o curso errático da dinâmica sociotemporal. Autorizam falar de descontinuidades e fragmentações da vida urbana que, reconhecemos, é uma outra forma de enunciar a metrópole contemporânea.

Mas há outros exemplos de adaptação e recriação funcional dos espaços ativos da cidade. Estou a pensar no caso do "minhocão", esse viaduto do centro de São Paulo, ${ }^{5}$ cujos usos diversos (autopista urbana queseconverte em espaço delazer familiar de proximidade no fim-de-semana) mostram uma inusitada capacidade de intervenção social e improvisão, como José Guilherme Magnani mostrou com enorme eloquência (MAGNANI, 2008). Se recuperássemos as referências de Marc Augé, diríamos que o "minhocão" sendo um não-lugar, revela um caráter oculto muito particular - como a aeroporto, tratado acima - derivado da capacidade para se metamorfosear em lugar, e depois, de novo, regressar à condição anterior de veloz pista automobilística. Este é território por excelência da personagem que Tiago Saraiva designa o "urbanita cyborg" na sua alegoria sobre o trajeto automóvel entre Oeiras e Cacém, na região metropolitana de Lisboa (SARAIVA, 2008). É um sinal da "elasticidade" da metrópole que ora se interrompe, ora retoma a sua forma primitiva, consoante o ritmo da alternância performativa de nervosos automobilistas e tranquilas famílias locais. É destas formas heterotópicas de lugares como o "minhocão" estrada-rua-espaço convivial/ quase-"pedaço" - que de descobre o instigante synoikismos ${ }^{6}$ da metrópole, parte do qual é revelada pela partilha de sentimentos e emoções como os que dão consistência ao espírito das (micro)territorialidades.

5 O "minhocão" refere-se ao Viaduto Presidente Costa e Silva, inaugurado em 1970 na cidade de S. Paulo. Com uma extensão de 3.400 metros, o viaduto liga a região da Praça Roosevelt (no centro da cidade) ao Largo Padre Péricles (na região da Barra Funda).

6 A expressão é tomada de Edward Soja (2000, p. 12-18) para significar o sentido clássico de "viver em conjunto", ou na mesma "casa" (oykos), em interdependência econômica e ecológica. 
Apesar das diferenças existentes, o "minhocão" reparte com as "ruínas modernas" a sua condição de espaço flexível e adaptável a finalidades outras. Os usos não previstos dos espaços urbanos que arquitetos e urbanistas tanto delatam, revelam um marcado sentido de "descoberta", quase diria de liberdade, e potencial criativo de cidadãos em demanda dos seus direitos à cidade. Mas é também uma prova da serendipidade que envolve nossas pesquisas em ciências sociais e humanas, muito em particular quando buscamos as relações entre o espaço, o corpo e o social.

Encontrar o espaço (e o espaço-tempo) da paragem no meio do ritmo acelerado da cidade contemporânea é abrir uma brecha nas convenções analíticas que tratam a metrópole apenas como aglomerado submetido ao princípio da célere velocidade e ininterrupta passagem. Ora, a cidade e a metrópole revelam cadências intermitentes e erráticas, quando vistas do lado das (micro)territorialidades. Com a ideia de cidade intermitente, pretendo significar a existência de "intervalos" no decurso da normalidade espacial e temporal da cidade (FORTUNA, 2009b). Implica uma noção de espaço urbano temporário que foi, por muito tempo, estranha a arquitetos e urbanistas para quem, em regra, $\mathrm{o}$ planejamento da cidade é concebido para o longo prazo. Implica igualmente uma noção de tempo curto ou descontínuo e feito de "intervalos" e "dobras" que cortam o curso linear do tempo abstrato (passado-presente-futuro).

Os espaços temporariamente urbanos da cidade são os que retiram sua qualidade e significação dessa temporalidade delimitada, como no caso do viaduto que acabamos de referir. É por serem ou se tornarem temporários que eles ganham importância e estabelecem relação com as funcionalidades diferenciadas da cidade. Configuram uma adaptação ao princípio da indeterminação e da contingência que, no limite, decorre do fim das metanarrativas e da recessão estratégica das megaestruturas. É o ambiente urbano típico por excelência do tempo de precariedade em que vivemos.

No caso de ações relacionadas com a ocupação temporária e precária de espaços, tanto podemos pensar nos "camelôs" como nas ocupações de residências. No início das experiências de ocupação de residências devolutas (nas décadas de 70 e 80 do século passado), a linguagem usada correntemente - "ocupas" - era manifestamente estigmatizante, em resultado da "anormalidade" (jurídica) da ocupação. Contudo, com a disseminação e continuação destas ações, a negatividade da linguagem acabou por ser gradualmente naturalizada, em parte devido às negociações entre os agentes diretos da ocupação, os poderes públicos e os proprietários, que em regra terminam na celebração de contratos, mas acima de tudo em consequência da maior transparência e do conhecimento que fomos obtendo do cotidiano comunitário de muitos dos atores envolvidos (VIANA, 2010).

Nestas referências à cidade intermitente vale incluir a noite como agente da configuração de outras territorialidades e comportamentos. A noite vista como "fronteira" (MELBIN, 1987; GWIAZDZINSKI, 2005) é o reconhecimento das diferentes temporalidades antagônicas da cidade. A sua simples e prosaica ocorrência, de acordo com o ciclo da natureza, basta para induzir a ressignificação dos lugares e, portanto, o sentido das representações sobre eles. O pensamento convencional lê a noite como night life (tempo e lugar de prazer, consumo, excesso, intoxication, enfim desordem e imoralidade). Mas 
o sentido alternativo da noite é a busca de sentidos reais dos lugares da cidade noturna. As ruas pedonais das cidades europeias que se convertem em bar, botequim e lugar de encontro e que alimentam infindável conversa de vizinhos são convites para uma nova atitude de pesquisa em torno das teias e cenas (micro)territoriais que alimentam (OLDENBURG, 1999). É importante entender a relação que a "anormalidade" destas territorialidades estabelece com a "normalidade" diurna e questionar todos os seus clichês e imagens estereotipadas. Sabemos que "muitas funções e práticas da vida diurna continuam sem interrupção noite dentro, independentemente da luz ou do escuro" (SCHLÖR, 1998, p. 9) e ao captar essa co-habitação, poderemos contribuir para esclarecer como a noite está colonizando o dia e, mais que isso, colonizando a cidade e a cultura urbana no seu todo. O regresso a Henri Lefebvre e à sua proposta de ritmanálise parece essencial neste contexto de descoberta das ritmicidades e das intermitências da cidade.

Nesta linha de ideias, dedico uma referência final ao modo como a precariedade dos espaços e as circunstâncias anômalas da vida de grupos e comunidades podem envolver a deslocalização do significado simbólico dos lugares identitários. Podemos designar estes casos de (micro)territorialidades identitárias de substituição. O primeiro exemplo a que me refiro resulta da chamada etnicização das paisagens urbanas com que se pretende caraterizar a presença regular de grupos de imigrantes em áreas delimitadas da cidade. Por razões residenciais, de comércio ou simples encontro, bairros inteiros ou praças da cidade revestem-se de sinais e conotações associadas diretamente a movimentos migratórios e à diáspora. Efeito da globalização, esta singular concentração espacial acaba funcionando como marca de identidade étnica e promove o sentido de "nação" que a desterritorialização ameaça (MARQUES; COSTA, 2007; GÓIS, 2011). Mas todas as desterritorializações se desdobram em reterritorializações que reconstroem o sentido de comunidade, mesmo que sob a forma de simulacro em que uma territorialidade sem território é objeto de marcação para sinalizar o substituto funcional do lugar "autêntico".

Um desenvolvimento desta situação pode ser ilustrado com o exemplo da "feira dos Lázaros", romaria de origem medieval da cidade de Coimbra. ${ }^{7}$ Mesmo depois das demolições dos anos 1940 que fizeram surgir ali os novos edifícios da Universidade, alterando drasticamente a fisionomia do entorno, a "feira" continua a realizar-se regularmente todos os anos no espaço histórico de origem. É, sem dúvida, um sinal da necessidade da espacialização dos rituais de autocelebração identitária que serve como instrumento de consolidação da relação de pertencimento a uma comunidade já dispersa. O lugar da festa não é hoje mais do que um topoi vernacular - a noção é tomada de Christine Boyer (1998) - decorrente da vontade das pessoas e do seu nostálgico espírito de lugar. Fazendo deste espaço uma âncora da identificação com a comunidade dos Lázaros, num retorno anual ritualizado, constitui uma poderosa manifestação de contestação e reconquista

7 A Feira dos Lázaros é apresentada como tradição medieval de Coimbra que desse modo celebra o bom acolhimento aos doentes de lepra. No penúltimo domingo antes da Páscoa, alguns populares vinham visitar os doentes (Lázaros) e na praça frente ao hospital - fundado a partir de recursos cedidos pelo reinado de Sancho I (1185-1211) - juntavam-se vendedores de produtos (sobretudo, doces e artesanato locais) que os visitantes ofereciam aos doentes. A romaria mantém-se até hoje, sensivelmente no mesmo espaço ocupado pelo antigo hospital. 
simbólica do território usurpado pela racionalidade da modernização urbana e o poder do estado, reconstruindo-o, temporariamente, em (micro)territorialidade significante.

As paisagens vernaculares constitutivas de um determinado sentido de lugar e dos costumes locais continuam a ser preservadas e recriadas nos mais variados lugares do mundo a partir de um sentimento de nostalgia que garante uma aproximação às raízes identitárias de comunidades que, como o Angelus Novus, têm motivos de sobra para ter receios do seu futuro. As (micro)territorialidades são a metáfora mais elucidativa para registar este desejo de se estar emocional e afetivamente juntos.

\section{CODA}

Procurei, no decurso destas páginas, fazer ressaltar implicações decorrentes destas espacializações significativas da vida social urbana que fomos designando por (micro) territorialidades. Estas constituem, como se pode concluir, um patrimônio do conhecimento crítico da socioantropologia urbana e da geografia cultural que carrega um enorme potencial de revisão dos saberes. O potencial de conhecimento que a análise das (micro)territorialidades contém para a produção do conhecimento crítico - a centralidade do corpo nas modernas configurações sociais urbanas é um dos mais significativos aspetos dessa análise - leva a admitir que o olhar produzido nestes enclaves de partilha de sentimentos e representações pode lançar uma nova esperança de afirmatividade política para os grupos subalternizados. Desse modo, podemos captar dimensões da realidade urbana metropolitana que vão sendo invisibilizadas à medida que esta se torna excessiva - na verdade, pós-humana.

A produção social da presença de grupos, discursos, práticas sociais, representações e territórios que constituem estas (micro)territorialidades é um ato não apenas epistemológico mas também ético e político de visibilização da realidade. Transporta consigo as vicissitudes e os desafios dos objetos de estudo rebeldes que não se deixam captar pela visão circunscrita das disciplinas acadêmicas convencionais. É, por esse efeito, também um objeto transgressor que instila desconforto e mobiliza renovadas energias de pesquisa inter/trans-disciplinar. As (micro)territorialidades constituem - e assim concluo - um desses objetos emergentes que urge consolidar conceitualmente e incluir nas agendas criativas da investigação universitária. A metáfora é, naturalmente, um dos passos iniciais possíveis para as (re)descobrir.

\section{REFERÊNCIAS}

ANDERSON, Benedict. Imagined communities: reflections on the origin and spread of nationalism. Londres: Verso, 1983.

ANDRADE, Carlos Sait Pereira de. Sentidos e nexos conceituais da cidade contemporânea. In: LIMA, Antônia Jesuíta (Org.). Cidades brasileiras: atores, processos e gestão pública. Belo Horizonte: Autêntica, 2007. p. 13-26. 
AUGÉ, Marc. Non-Lieux: introduction à une anthropologie de la surmodernité. Paris: Seuil, 1992.

BENJAMIN, Walter. Theses on the philosophy of history. In: BENJAMIN, Walter. Illuminations: essays and reflections. (Org. de Hannah Arendt). Londres e Nova Iorque: Harcourt Brace Jovanovich, 1968 [1940]. p. 253-64.

BOYER, Christine. The city of collective memory: its historical imagery and architectural entertainments. Cambridge (Mass.): MIT Press, 1998.

CLOUGH, Patricia; HALLEY, Jean (Orgs.). The affective turn: theorizing the social. Londres: Duke University Press, 2007.

COHEN, Eric. The structural transformation of the kibbutz. In: KRAUSZ, E. (Org.). The sociology of the kibbutz: studies of Israeli society. Londres e New Brunswick: Transaction Books, 1983. v. 2. p. 75-114.

DEGEN, Monica. Sensing cities: regenerating public life in Barcelona and Manchester. Nova Iorque: Routledge, 2008.

EDENSON, Tim. Industrial ruins: space, aesthetics and materiality. Nova Iorque: Berg, 2005.

FORTUNA, Carlos. La ciudad de los sonidos: una heurística de la sensibilidade en los paisages urbanos contemporâneos. Cuadernos de Antropología Social, Buenos Aires, n. 30, p. 39-58, 2009a.

FORTUNA, Carlos. Cidade e urbanidade. In: FORTUNA, Carlos; LEITE, Rogerio P. (Orgs.). Plural de cidade: novos léxicos urbanos. Coimbra: Almedina, 2009b, p. 83-97.

FORTUNA, Carlos. Narrativas sobre a metrópole centenária: Simmel, Hessel e Seabrook. Cadernos Metrópole, São Paulo, v. 13, n. 26, p. 379-93, 2011.

FOUCAULT, Michel. Other spaces: the principles of heterotopia. Lotus International, 1986, 48/49, p. 9-17. GWIAZDZINSKI, Luc. La nuit: Dernière fronteire de la ville. La Tour d'Aigues: Éditions de l'Aube, 2005.

GÓIS, Pedro Madeira. A construção secular de uma identidade étnica transnacional: a cabo-verdianidade. Tese de Doutorado. Coimbra: Faculdade de Economia da Universidade de Coimbra, 2011.

GOMES, Edvânia. Recortes de paisagens na cidade do Recife: uma abordagem geográfica. Tese de Doutorado. São Paulo: Universidade de São Paulo, 1997.

HETHERINGTON, Kevin. Expressions of identity: space, performance, politics. Londres: Sage, 1998.

JAMESON, Fredric. Demographies of anonymous. In: DAVIDSON, Cynthia (Org.). Anyone. Nova Iorque: Rizzolo, 1991. p. 56-57.

JEUDY, Henri-Pierre; JACQUES, Paola Berenstein (Orgs.). Corpos e cenários urbanos: territórios urbanos e políticas culturais. Salvador: EDUFBA, 2006.

LATOUR, Bruno. When things strike back: a possible contribution of 'science studies'. British Journal of Sociology, v. 51, n. 1, p. 107-23, 2000.

LEFEBVRE, Henri. The production of space. Oxford: Blackwell, 1991.

Éléments de rythmanalys: introduction à la connaissance des rythmes. Paris: Syllepse, 2002.

MAFFESOILI, Michel. Le temps des tribus: le déclin de l'individualisme dans les sociétés de masse. Paris: Méridiens-Klincksieck, 1988.

MAGNANI, José Guilherme. Narradores urbanos: antropologia urbana e etnografia nas cidades brasileiras. São Paulo; Porto Alegre: Laboratório de Antropologia Social - PPGAS-UFRGS. Direção de Cornelia Eckert e Ana Luiza Carvalho da Rocha, 2008. (Video).

MAKIMOTO, Tsugio; MANNERS, David. Digital nomads. Chichester: John Willey, 1997.

MARQUES, Maria Margarida; COSTA, Francisco Lima da. Building a market of ethnic references: activism and diversity in multicultural settings in Lisbon. In: RATH, Jan (Org.). Tourism, ethnic diversity and the city. Londres: Routledge, 2007. p. 181-98. 
MELBIN, Murray. Night as frontier: colonizing the world after dark. Nova Iorque: The Free Press; Londres: Collier Macmillan Publishers, 1987.

OLDENBURG, Ray. The great good place: cafés, coffee shops, bookstores, bars, hair salons and other hangouts at the heart of a community. Cambridge: Da Capo Press, 1999.

REEH, Henrik. Arrivals and departures: travelling to the airports of Berlin. In: STAIGER, Uta; STEINER, Henriette; WEBBER, Andrew (Orgs.). Memory culture and the contemporary city: building sites. Nova Iorque; Londres: Palgrave, 2009, p. 52-68.

RODAWAY, Paul. Sensuous geographies. Londres: Routledge, 1994.

SANSOT, Pierre. Poétique de la ville. Paris: Petite Bibliothèque Payot, 1994.

SARAIVA, Tiago. Cidadão cyborg. In: CABRAL, Manuel; SILVA, Filipe Carreira da; SARAIVA, Tiago (Orgs.). Cidade \& cidadania: governança urbana e participação cidadã em perspectiva comparada. Lisboa: Imprensa de Ciências Sociais, 2008. p. 107-28.

SASSEN, Saskia. Territory, authority, rights: from medieval to global assemblages. Princeton; Oxford: Princeton University Press, 2006.

. The global street comes to Wall Street. In: Possible futures. Disponível em: <http:/ /www.possiblefutures.org/2011/11/22/the-global-street-comes-to-wall-street/>. Acesso em: 22 nov. 2011.

SCHLÖR, Joachin. Nights in the big city: Paris, Berlin, London, 1840-1930. Londres: Reaktion Books, 1998.

SCHMALENBACH, Herman. Communion: a sociological category. In Lüschen, Günther; Stone, Gregory (Orgs.), Herman Schmalenbach on society and experience. Chicago; Londres: The University of Chicago Press, 1977 [1922].

SENNETT, Richard. Destructive Gemeinshaft. In: Birnbaum, Norman, (Org.). Beyond the crisis. Oxford: Oxford University Press, 1977. p. 171-97.

SOJA, Edward. Postmetropolis: critical studies of cities and regions. Oxford e Victoria: Blackwell Publishers, 2000.

STEWART, Kathleen. Ordinary affects. Durham; Londres: Duke University Press, 2007.

THAI, Wong Chong. Cacophony: gratification or innovation. In: Nalbantoğlu, Gülsüm Baydar; Thai, Wong Chong (Orgs.), Postcolonial space(s). Nova Iorque: Princeton Architectural Press, 1997. p.131-39.

TÖNNIES, Ferdinand. Comunidad y asociación. Barcelona: Ediciones Península, 1972 [1887].

TUAN, Yu-Fu. Espaço e lugar: a perspectiva da experiência. São Paulo: Difel, 1983.

URRY, John. Sociology beyond societies. Londres: Routledge, 2000.

VIANA, Leandro Fernandes. Cidade reconquistada: uma etnografia da (in)visibilidade de outros espaços urbanos. Dissertação de Mestrado. Coimbra: Faculdade de Economia da Universidade de Coimbra, 2010.

Recebido em 22/01/2012

Aceito para publicação em 01/03/ 2012 